\title{
Effects of Caffeine on Physical and Cognitive Performance: A Brief Review
}

\author{
Daniel Jaffe ${ }^{1 *}$, Jennifer Hewit ${ }^{1}$, Nils Pilotte ${ }^{2}$, Garrett Beck ${ }^{1}$ and Marissa Karp ${ }^{1}$ \\ ${ }^{1}$ Department of Physical Education, United States Military Academy, USA \\ ${ }^{2}$ Molecular and Cellular Biology Program, University of Massachusetts, USA

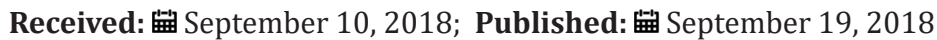 \\ *Corresponding author: Daniel Jaffe, Department of Physical Education, United States Military Academy, USA
}

\section{Editorial}

Caffeine is one of the most extensively studied and widely used ergogenic aid capable of improving many aspects of sport performance and cognitive abilities [1-12]. Some of the acute effects of caffeine supplementation are increases anaerobic power output and performance, increased muscular strength, endurance, and power, improvements to aerobic endurance, reduced fatigue, decreased RPE and pain, increased voluntary workload, and increased alertness [1-8]. Chronic caffeine consumption has also been shown to have a positive effect on long term memory, locomotor improvements, and overall mood state [9-11]. Some of the positive effects of athletic performance attributed to caffeine ingestion can be explained by its ability to moderate insulin sensitivity, increase plasma free fatty acids (FFAs), and increase plasma epinephrine [12]. These results demonstrated that caffeine consumption can allow more glucose and FFAs to be available in the blood for immediate energy. Furthermore, caffeine has been shown to increase calcium release from the sarcoplasmic reticulum of muscle fibers, which could result in increased actinmyosin binding and therefore increased force production [12]. Some of the acute physical effects of caffeine supplementation are increases anaerobic power output and performance, increased muscular strength, endurance and power, improvements to aerobic endurance, and reduced fatigue [1,3-6,8]. Additionally, acute caffeine consumption also enhances cognitive function during physical tasks as demonstrated through a reduction in self-reported rate of perceived exertion (RPE) and pain perception, increasing voluntary choice of work load, and increasing alertness $[2,7,9]$. As demonstrated in a multitude of studies, caffeine is used by athletes prior to competition because of the belief that it may improve performance. Beck et al. [1] performed an analysis of the immediate effects of caffeine supplementation on athletic performance [1]. During the study, 37 resistance-trained males (21+/-2 years) performed repeated Wingate Anaerobic Tests (WAnT) and multiple one repetition maximum (1RM) and additional submaximal assessments to evaluate the effects of caffeine on power, strength, and muscular endurance. Researchers noted a significant increase in the $1 \mathrm{RM}$ on bench press $(2.1 \%$ increase; $\mathrm{p}<0.05)$ for the experimental group relative to the placebo. However, no significant differences in performance were noted between the groups in any other category [1].

The results of this study demonstrated that ingesting a caffeine-containing supplement prior to performing an athletic event conferred a benefit to upper-body strength. According to the authors, future studies should examine the acute effects of various dosages of caffeine on strength, muscular endurance, and anaerobic capabilities in both trained and untrained subjects [1]. Chronic caffeine consumption has not been shown to effect physical performance and has actually been shown to decrease performance when caffeine ingestion ends after prolonged use [9]. Research has also shown that chronic supplementation may have a positive effect on long term memory, locomotor improvements, and overall mood state; however, has been shown to negatively impact sleep and cause headaches when caffeine consumption ends [9-12s]. James et al. [9] evaluated the acute and chronic effects of caffeine ingestion on mood, performance, headache, and sleep, and how these could change from caffeine withdrawal Utilizing a double-blind, placebo controlled, crossover experiment subjects were then tested on several objective indices of performance, and asked to self-report mood, headache, and sleep patterns. The results of the experiment demonstrated that there was no evidence of performance increase in either chronic or acute caffeine consumption [9]. However, performance was found to be impaired when caffeine consumption ceased following habitual use. Caffeine withdrawal was also associated with reported increases in headache frequency and severity, and with reports of sleeping longer and more soundly. Subjects reported feeling more alert after acute consumption of caffeine but feeling less alert overall with chronic use [9]. These findings demonstrated that the negative side-effects that correspond with caffeine withdrawal may outweigh and positive effects of alertness [9]. 


\section{References}

1. Beck TW, Housh TJ, Schmidt RJ, Johnson GO, Housh DJ, et al. (2011) The acute effects of a caffeine-containing supplement on strength, muscular endurance, and anaerobic capabilities. Journal of Strength and Conditioning Research 20(3): 506-510.

2. Arazi H, Hoseinihaji M, Eghbali, E (2016) The effects of different doses of caffeine on performance, rating of perceived exertion, and pain perception in teenage female karate athletes. Brazilian Journal of Pharmaceuticals Sciences 52(4): 685-692.

3. Glaister M, Muniz Pumares D, Patterson SD, Foley P, McInnes G (2015) Caffeine supplementation and peak anaerobic power output. European journal of sport science 15(5): 400-406.

4. Schneiker KT, Bishop DJ, Dawson B, Hackett LP (2006) Effects of caffeine on prolonged intermittent-sprint ability in team-sport athletes. Medicine and Science in Sports and Exercise 38(3): 578-585.

5. Del Coso J, Salinero JJ, Gonzalez Millan C (2012) Dose response effects of a caffeine containing energy drink on muscle performance: A repeated measures design. Journal of the International Society of Sports Nutrition $9(1): 21$.

6. Paton CD, Lowe T, Irvine A (2010) Caffeinated chewing gum increases repeated sprint performance and augments increases in Testosterone

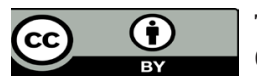

This work is licensed under Creative

Commons Attribution 4.0 License

To Submit Your Article Click Here:

Submit Article in competitive cyclists. European Journal of Applied Physiology 110(6): 1243-1250.

7. Cook CC, Beaven M, Kilduff LP, Drawer S (2012) Acute caffeine ingestion's increase in voluntarily chosen resistance-training load after limited sleep. International Journal of Sport Nutrition and Exercise Metabolism 22(3): 157-164.

8. Desbrow B, Biddulph C, Devlin B, Grant DG, Anoopkumar Dukie S, et al. (2011) The effects of different doses of caffeine on endurance cycling time trial performance. Journal of Sports Sciences 30(2): 115-120.

9. James JE (2000) Acute and chronic effects of caffeine on performance, mood, headache, and sleep. Neuropsychobiology 38(1): 32-41.

10. Hamaleers PM, Van Boxtel MJ, Hogervorst E, Riedel WJ, Houx PJ, et al. (2000) Habitual caffeine consumption and its relation to memory, attention, planning capacity, and psychomotor performance across multiple age groups. Human Psychopharmacology: Clinical and Experimental 15(8): 573-581.

11. Judelson DA, Armstrong LE, Sokmen B, Roti MW, Casa DJ, et al. (2005) Effect of chronic caffeine intake on choice reaction time, mood, and visual vigilance. Physiology and Behavior 85(5): 629-634.

12. Keijzers GB, De Galan BE, Tack CJ, Smits P (2002) Caffeine can decrease insulin sensitivity in humans. Diabetes Care 25(2): 364-369.

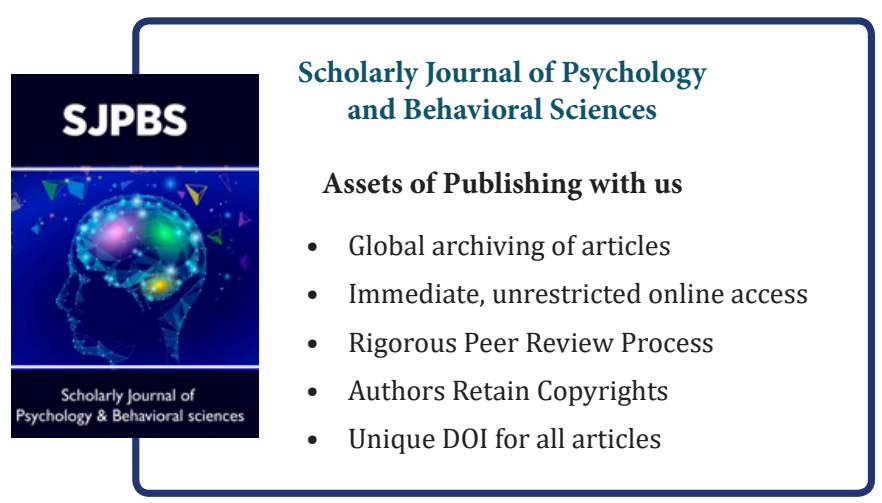

